\title{
North-south gradients in plasma concentrations of B-vitamins and other components of one-carbon metabolism in Western Europe: results from the European Prospective Investigation into Cancer and Nutrition (EPIC) Study
}

Simone J. P. M. Eussen ${ }^{1,2 *}$, Roy M. Nilsen ${ }^{3}$, Øivind Midttun ${ }^{4}$, Steinar Hustad ${ }^{2}$, Noortje IJssennagger ${ }^{5}$, Klaus Meyer ${ }^{4}$, Åse Fredriksen ${ }^{4}$, Arve Ulvik ${ }^{4}$, Per M. Ueland ${ }^{2,6}$, Paul Brennan ${ }^{7}$, Mattias Johansson ${ }^{7}$, Bas Bueno-de-Mesquita ${ }^{8,9}$, Paolo Vineis ${ }^{10}$, Shu-Chun Chuang ${ }^{10}$, Marie Christine Boutron-Ruault ${ }^{11}$, Laure Dossus $^{11}$, Florence Perquier ${ }^{11}$, Kim Overvad ${ }^{12}$, Birgit Teucher ${ }^{13}$, Verena A. Grote $^{13}$, Antonia Trichopoulou ${ }^{14,15}$, George Adarakis ${ }^{15}$, Maria Plada ${ }^{15}$, Sabina Sieri ${ }^{16}$, Rosario Tumino ${ }^{17}$, Maria Santucci de Magistris ${ }^{18}$, Martine M. Ros $^{8,19}$, Petra H. M. Peeters ${ }^{10,20}$, Maria Luisa Redondo ${ }^{21}$, Raul Zamora-Ros ${ }^{22}$, Maria-Dolores Chirlaque ${ }^{23,24}$, Eva Ardanaz ${ }^{24,25}$, Emily Sonestedt ${ }^{26}$, Ulrika Ericson ${ }^{26}$, Jörn Schneede ${ }^{27}$, Bethany van Guelpen ${ }^{28}$, Petra A. Wark ${ }^{10}$, Valentina Gallo ${ }^{10,29}$, Teresa Norat ${ }^{10}$, Elio Riboli ${ }^{10}$ and Stein Emil Vollset ${ }^{1}$

${ }^{1}$ Department of Public Health and Primary Health Care and Section for Pharmacology, Institute of Medicine, Faculty of Dentistry and Medicine, University of Bergen, 5021 Laboratory Building, 9th Floor, Bergen, Norway

${ }^{2}$ Section for Pharmacology, Institute of Medicine, University of Bergen, Bergen, Norway

${ }^{3}$ Centre for Clinical Research, Haukeland University Hospital, Bergen, Norway

${ }^{4}$ Bevital A/S, Bergen, Norway

${ }^{5}$ Division of Human Nutrition, Wageningen University, Wageningen, The Netherlands

${ }^{6}$ Laboratory of Clinical Biochemistry, Haukeland University Hospital, Bergen, Norway

${ }^{7}$ International Agency for Research on Cancer, Lyon, France

${ }^{8}$ National Institute for Public Health and the Environment (RIVM), Bilthoven, The Netherlands

${ }^{9}$ Department of Gastroenterology and Hepatology, University Medical Centre, Utrecht, The Netherlands

${ }^{10}$ Department of Epidemiology and Biostatistics, School of Public Health, Faculty of Medicine, Imperial College,

London, UK

${ }^{11}$ Inserm, Centre for Research in Epidemiology and Population Health, U1018, Institut Gustave Roussy, F-94805, and Paris South University, UMRS 1018, F-94805 Villejuif, France

${ }^{12}$ Section of Epidemiology, Department of Public Health, Aarbus University, Aarbus, Denmark

${ }^{13}$ German Cancer Research Center (DKFZ), Heidelberg, Germany

${ }^{14}$ WHO Collaborating Center for Food and Nutrition Policies, Department of Hygiene, Epidemiology and Medical Statistics,

University of Athens Medical School, Athens, Greece

${ }^{15}$ Hellenic Health Foundation, Athens, Greece

${ }^{16}$ Nutritional Epidemiology Unit, Fondazione IRCCS Istituto Nazionale Tumori, Milano, Italy

${ }^{17}$ Cancer Registry and Histopathology Unit, "Civile - M.P. Arezzo" Hospital, ASP, Ragusa, Italy

${ }^{18}$ Department of Clinical and Experimental Medicine, Federico II University, Naples, Italy

${ }^{19}$ Department of Epidemiology, Biostatistics and HTA, Radboud University Nijmegen Medical Centre, Nijmegen,

The Netherlands

${ }^{20}$ Julius Center, University Medical Center, Utrecht, The Netherlands

${ }^{21}$ Public Health Directorate, Asturias, Spain

${ }^{22}$ Unit of Nutrition, Environment and Cancer, Cancer Epidemiology Research Programme, Catalan Institute of Oncology (ICO-IDIBELL), Barcelona, Spain

${ }^{23}$ Department of Epidemiology, Murcia Regional Health Authority, Murcia, Spain

Abbreviations: CRC, colorectal cancer; EPIC, European Prospective Investigation into Cancer and Nutrition; GC, gastric cancer; LC, lung cancer; MMA, methylmalonic acid; MTHFR, methylenetetrahydrofolate reductase; PC, pancreatic cancer; PL, pyridoxal; tHcy, total homocysteine.

*Corresponding author: S. J. P. M. Eussen, fax +4755 974605, email simone.eussen@farm.uib.no 
${ }^{24}$ Consortium for Biomedical Research in Epidemiology and Public Health (CIBER Epidemiología y Salud Pública CIBERESP), Granada, Spain

${ }^{25}$ Navarre Public Health Institute, Pamplona, Spain

${ }^{26}$ Department of Clinical Sciences, Malmö, Lund University, Lund, Sweden

${ }^{27}$ Department of Pharmacology and Clinical Neuroscience, Umeå University, Umeå, Sweden

${ }^{28}$ Department of Medical Biosciences, Umeå University, Umeå, Sweden

${ }^{29}$ Social and Environmental Health Research, London School of Hygiene and Tropical Medicine, London, UK

(Submitted 22 May 2012 - Final revision received 4 October 2012 - Accepted 12 October 2012 - First published online 11 December 2012)

\section{Abstract}

Different lifestyle patterns across Europe may influence plasma concentrations of B-vitamins and one-carbon metabolites and their relation to chronic disease. Comparison of published data on one-carbon metabolites in Western European regions is difficult due to differences in sampling procedures and analytical methods between studies. The present study aimed, to compare plasma concentrations of one-carbon metabolites in Western European regions with one laboratory performing all biochemical analyses. We performed the present study in the European Prospective Investigation into Cancer and Nutrition (EPIC) cohort among 5446 presumptively healthy individuals. Quantile regression was used to compare sex-specific median concentrations between Northern (Denmark and Sweden), Central (France, Germany, The Netherlands and United Kingdom) and Southern (Greece, Spain and Italy) European regions. The lowest folate concentrations were observed in Northern Europe (men, $10.4 \mathrm{nmol} / 1$; women, $10.7 \mathrm{nmol} / \mathrm{l}$ ) and highest concentrations in Central Europe. Cobalamin concentrations were slightly higher in Northern Europe (men, $330 \mathrm{pmol} / \mathrm{l}$; women, $352 \mathrm{pmol} / \mathrm{l}$ ) compared with Central and Southern Europe, but did not show a clear north-south gradient. Vitamin $\mathrm{B}_{2}$ concentrations were highest in Northern Europe (men, 22.2 nmol/1; women, $26.0 \mathrm{nmol} / \mathrm{l})$ and decreased towards Southern Europe $\left(P_{\text {trend }}<0.001\right)$. Vitamin $\mathrm{B}_{6}$ concentrations were highest in Central Europe in men $(77.3 \mathrm{nmol} / \mathrm{l})$ and highest in the North among women $(70.4 \mathrm{nmol} / \mathrm{l})$, with decreasing concentrations towards Southern Europe in women $\left(P_{\text {trend }}<0.001\right)$. In men, concentrations of serine, glycine and sarcosine increased from the north to south. In women, sarcosine increased from Northern to Southern Europe. These findings may provide relevant information for the study of regional differences of chronic disease incidence in association with lifestyle.

\section{Key words: B-vitamins: Amino acids: One-carbon metabolism: Europe}

One-carbon metabolism involves transfer of one-carbon units from the amino acids serine or glycine to tetrahydrofolate to form methylenetetrahydrofolate. Methylenetetrahydrofolate is either used for the synthesis of thymidine and purines, which are building blocks for DNA, or it is reduced to methyltetrahydrofolate, which re-methylates homocysteine to methionine. Methionine is activated to $S$-adenosylmethionine, the major methyl group donor for the methylation reactions of many substrates. The vitamins $B_{2}, B_{6}$ and $B_{12}$ function as cofactors for enzymes, catalysing the conversion of homocysteine to methionine or cystathionine and cysteine. Choline is another source of one-carbon units. It is converted to betaine, which in the liver and kidneys serves as a substrate in another reaction re-methylating homocysteine to methionine, with dimethylglycine as a product. Sarcosine is formed from dimethylglycine or during the metabolism of excess methionine, and can be further metabolised to glycine, which is an important source of serine ${ }^{(1)}$.

B-vitamins, related amino acids and variants of genes coding for enzymes involved in one-carbon metabolism may influence cellular growth, differentiation and function, which provides plausible biological background that links onecarbon metabolism to various disease outcomes. Although results from observational and experimental studies have not always been consistent, the majority of studies suggest that B-vitamins and other components related to one-carbon metabolism are associated with neural tube defects ${ }^{(2)}$, the metabolic syndrome ${ }^{(3,4)}, \mathrm{CVD}^{(5)}$, cognitive impairment ${ }^{(6)}$, bone health ${ }^{(7)}$ and different types of cancer ${ }^{(8,9)}$.

The methylenetetrahydrofolate reductase (MTHFR) $677 \mathrm{C} \rightarrow \mathrm{T}$ polymorphism ${ }^{(10)}$ and lifestyle factors such as smoking $^{(11)}$ and alcohol consumption ${ }^{(12,13)}$ may affect blood concentrations of B-vitamins and other components of onecarbon metabolism ${ }^{(14)}$. There is a great diversity in dietary and lifestyle patterns among European countries ${ }^{(15-17)}$, which are likely to influence plasma status of nutrients and the subsequent risk of morbidity and mortality ${ }^{(18)}$. For example, a Mediterranean diet - rich in plant foods and folate - in combination with healthy lifestyle factors such as abstaining from smoking, moderate alcohol consumption and being physically active, has been associated with a lower mortality rate ${ }^{(19)}$.

The European Prospective Investigation into Cancer and Nutrition (EPIC) and a number of multicentre studies have been conducted to investigate dietary intake or blood concentrations of B-vitamins as determinants of health in Europe. These studies show relatively low intake of B-vitamins in Scandinavian countries, the Netherlands, Germany and Greece $^{(20,21)}$. However, no major differences in B-vitamin intake across EPIC study centres have been observed ${ }^{(22,23)}$. The SENECA (Survey in Europe on Nutrition and the Elderly, a Concerted Action) study showed large differences in plasma vitamin status between study centres, with vitamin $\mathrm{B}_{6}$ concentrations being lowest in Greece and Denmark ${ }^{(24)}$, but no clear 
geographical patterns were observed ${ }^{(25)}$. A summary of thirtyone European studies on plasma/serum B-vitamins revealed relatively low folate concentrations in Norway and Sweden, while lower vitamin $B_{12}$ concentrations were observed in the Netherlands, Germany, Czech Republic and Italy compared to other countries ${ }^{(21)}$.

Data on plasma concentrations of components related to one-carbon metabolism in European countries are inconclusive. Comparison of plasma concentrations between individual European studies is difficult due to different blood sampling protocols and large inter-assay variability by laboratory methods used in different studies ${ }^{(26)}$. The present study aimed to investigate patterns in plasma B-vitamin status, amino acids and related methylamines in Western European regions, while eliminating variability in sampling procedures and assay methods, as all biochemical analyses were carried out in citrate plasma by a single laboratory. With data on 5446 individuals from the EPIC cohort, this is the largest population to date to compare patterns across European regions and in a population with no mandatory fortification with folic acid or other B-vitamins.

\section{Methods}

\section{Study population}

The EPIC study investigates associations between diet, lifestyle and cancer risk ${ }^{(27)}$ among individuals recruited between 1992 and 2000 living in ten European countries. The present crosssectional study comprises the control individuals who were matched to cancer cases participating in four nested casecontrol sub-studies on gastric- (GC, $n$ 805), colorectal- (CRC, $n$ 2408), lung- (LC, $n$ 1778) and pancreatic cancer (PC, $n$ 455). Matching criteria were sex, age group ( \pm 2.5 years), study centre and date of blood collection (all studies), and additionally for time of blood collection and fasting status in the PC study. Blood samples from EPIC-Oxford and EPIC-Norway centres were exposed to ambient temperatures for up to $48 \mathrm{~h}$. As some B-vitamins and related metabolites are unstable under such conditions ${ }^{(26,28)}$, all EPIC-Oxford ( $n$ 221) and EPIC-Norway ( $n$ 11) samples were excluded from the present analyses. Participants in the present study were from Greece ( $n$ 288, recruited from studies on GC ( $n$ 32), CRC ( $n$ 51), LC ( $n$ 182) and PC ( $n$ 23), Spain ( $n$ 638, recruited from studies on GC ( $n$ 107), CRC ( $n$ 238), LC ( $n$ 254) and PC ( $n$ 39)), Italy ( $n$ 799, recruited from studies on GC ( $n$ 186), CRC ( $n$ 294), LC ( $n$ 277) and PC $(n$ 42)), France ( $n$ 133, recruited from studies on GC $(n$ 10), CRC ( $n$ 60), LC ( $n$ 48) and PC $(n$ 15)), Germany ( $n 797$ recruited from studies on GC ( $n$ 117), CRC ( $n$ 313), LC $(n$ 312) and PC $(n 55)$ ), The Netherlands ( $n$ 650, recruited from studies on GC ( $n$ 78), CRC ( $n$ 297), LC ( $n$ 237) and PC ( $n$ 38)), United Kingdom ( $n$ 919, recruited from studies on GC ( $n$ 104), CRC ( $n$ 421), LC $(n$ 350) and PC $(n$ 44)), Denmark ( $n$ 500, recruited from studies on GC ( $n$ 43), CRC ( $n$ 373), LC $(n 0)$ and PC $(n$ 84)) and Sweden $(n 722$, recruited from studies on GC ( $n$ 128), CRC $(n$ 361), LC $(n$ 118) and PC ( $n$ 115)). The present study was conducted according to the guidelines laid down in the Declaration of Helsinki, and all procedures involving human subjects were approved by the ethical review boards from the International Agency for Research on Cancer; all local participating centres approved the study. Written informed consent was obtained from all the subjects.

\section{Data collection}

Blood sampling and laboratory analyses. In each of the recruitment centres, fasting (42.8\% (6.6\% in North, 30.7\% in Central and $5.5 \%$ in Southern Europe)) or non-fasting (47.2\% (6.8\% in North, $14.3 \%$ in Central and $26.1 \%$ in Southern Europe)) blood samples of at least $30 \mathrm{ml}$ were drawn at baseline between March 1991 and April 1999. In 9.9\% (9.1\% in North, $0.7 \%$ in Central and $0.1 \%$ in Southern Europe) information on prandial status was missing. Samples were stored at $5-10^{\circ} \mathrm{C}$, protected from light and transported to local laboratories for processing and aliquoting as previously described $^{(27,29)}$. In all countries, except Denmark and Sweden, blood was separated into $0.5 \mathrm{ml}$ aliquots (serum, plasma, erythrocytes and buffy coat for DNA extraction) and stored into plastic CBS straws ${ }^{\mathrm{TM}}$, which were heat sealed and stored in liquid $\mathrm{N}_{2}\left(-196^{\circ} \mathrm{C}\right)$. Half of the aliquots were stored at the local study centre and the other half in the central EPIC biorepository at the International Agency for Research on Cancer (Lyon, France). In Denmark, aliquots of $1.0 \mathrm{ml}$ were stored locally at $-150^{\circ} \mathrm{C}$ under $\mathrm{N}_{2}$ vapour. In Sweden, samples were stored at $-80^{\circ} \mathrm{C}$.

For the present study, blood samples collected into citrate plasma tubes were used for biochemical analyses in the laboratory of Bevital AS (http://www.bevital.no). The present study included B-vitamins (folate, vitamins $\mathrm{B}_{2}$ and $\mathrm{B}_{6}$ species, vitamin $\mathrm{B}_{12}$ and its marker methylmalonic acid (MMA)), methylamines (choline, betaine and dimethylglycine) and amino acids (total homocysteine (tHcy), methionine, total cysteine, cystathionine, serine, glycine and sarcosine). Vitamin $\mathrm{B}_{2}$ measures included plasma concentrations of riboflavin and FMN; pyridoxal-5'-phosphate, pyridoxal (PL) and 4-pyridoxic acid were measures of vitamin $\mathrm{B}_{6}$ status. Vitamin $\mathrm{B}_{2}$ and $\mathrm{B}_{6}$ species and methylamines were determined by LC-MS/ $\mathrm{MS}^{(30-33)}$, and MMA and amino acids by GC-MS/MS based on methylchloroformate derivatisation ${ }^{(33,34)}$. Vitamin $\mathrm{B}_{12}$ was determined with a Lactobacillus leichmannii microbiological method $^{(35)}$ and plasma folate with a Lactobacillus casei microbiological method, both adapted to a microtitre plate format, and analysis was carried out on a robotic workstation (Micro-lab AT plus 2; Hamilton Bonaduz AG) ${ }^{(36)}$. Withinand between-day $\mathrm{CV}$ for folate were $3-20 \%{ }^{(36)}, 3-20 \%$ for vitamin $\mathrm{B}_{2}$ vitamers $^{(32)}, 6-22 \%$ for vitamin $\mathrm{B}_{6}$ vitamers $^{(32)},<5 \%$ for vitamin $\mathrm{B}_{12}$, tHcy and $\mathrm{MMA}^{(34,35)},<5 \%$ for choline, betaine and dimethylglycine ${ }^{(31)}$ and $<5 \%$ for the remaining amino $\operatorname{acids}^{(33,34)}$.

FMN was not measured in the LC study; serine, glycine and sarcosine were not measured in gastric- and colorectal studies; and the methylamines were not measured in LC and PC studies.

The MTHFR $677 \mathrm{C} \rightarrow \mathrm{T}$ polymorphism (rs 1801133) was determined by matrix-assisted laser desorption/ionisation 
time-of-flight $\mathrm{MS}^{(37,38)}$ in the studies on GC, CRC and LC. Data on the MTHFR $677 \mathrm{C} \rightarrow \mathrm{T}$ polymorphism were available for $87 \cdot 8 \%$ of the participants (664 missing).

Descriptive variables. Data on age, sex and information on lifestyle factors known to affect B-vitamin status, such as smoking status ${ }^{(11)}$ (never, former, current, missing) and alcohol consumption, were collected at enrolment in the study. Total alcohol consumption (pure ethanol in $\mathrm{g} / \mathrm{d}$ ) at baseline, which represented consumption over the 12 months before enrolment in the EPIC cohort, was determined from lifestyle questionnaires. The present study distinguishes between abstainers, very light or occasional consumers $(0 \cdot 1-<4.9 \mathrm{~g} / \mathrm{d})$, moderate consumers $(4.9-<30 \mathrm{~g} / \mathrm{d})$ and heavy consumers $(\geq 30 \mathrm{~g} / \mathrm{d})$. Data on total alcohol intake were available for 99.6\% of the participants (twenty-two missing).

\section{Statistical methods}

Statistical analyses were conducted for the total study population, as well as within each European region (North: Sweden and Denmark; Central: France, United Kingdom, the Netherlands and Germany; South: Italy, Spain and Greece) and country. Using the PROC CORR SAS procedure, we calculated Spearman rank correlation coefficients between metabolites, adjusting (using a PARTIAL statement) for age, sex, sub-study and prandial status. Because riboflavin may be formed from $\mathrm{FMN}^{(39)}$, we considered the sum of riboflavin and FMN as a measure for vitamin $\mathrm{B}_{2}$ status. As PL may be formed from pyridoxal- 5 -phosphate in blood and 4-pyridoxic acid from PL in the liver ${ }^{(40)}$, we considered the sum of pyridoxal-5'-phosphate, PL and 4-pyridoxic acid to be a measure of vitamin $\mathrm{B}_{6}$ status. Some metabolites were not normally distributed. Therefore, differences in crude concentrations of the B-vitamins between demographic and lifestyle groups were assessed by non-parametric tests, Mann-Whitney $U$ tests or $\chi^{2}$ tests where appropriate.

Because blood concentrations of several metabolites varied according to sub-studies as well as age groups, medians of one-carbon-related nutrients across European regions were described and estimated by using a direct standardisation $\operatorname{method}^{(41)}$. First, the total population was considered as 'a standard' and was distributed into all possible combinations of three age groups ( $\leq 60,60-\leq 70$ and $>70$ years), four sub-studies (GC, CRC, PC and LC) and three groups of prandial status (fasting, non-fasting and missing information on prandial status), which comprises thirty-six subgroups altogether. For each combination, we estimated the relative frequency or weight $(w)$ from the total population. Second, the median $(m)$ of each metabolite was estimated for each combination of sub-study and age in each region by using quantile regression models. Finally, the standardised median of each metabolite within each region was defined as the weighted average of the respective median $m$, weighted by $w$. This procedure was also used for calculating the 5 th and the 95th percentiles of the metabolites. Tests for trends in plasma concentrations of the one-carbon metabolites across the European regions were assessed by median regression (i.e. quantile regression), in which we regressed crude blood concentrations of the metabolites against the European region, adjusted for age groups, sub-studies and prandial status. $P$ for difference between regions was assessed by the Wald test.

We further investigated proportional differences in metabolite concentrations across the three European regions at the $0.025,0.05,0.25,0.50,0.75,0.95$ and 0.975 quantiles of the outcome variables ${ }^{(42)}$. The results were plotted graphically, displaying the percentage differences between the European regions (with Southern Europe as the reference) $v$. the metabolite concentrations at each quantile cut-off. These models are adjusted for age, sex, sub-study and prandial status. In addition, we investigated whether relations of plasma folate and tHcy with the MTHFR $677 \mathrm{C} \rightarrow \mathrm{T}$ polymorphism differed across regions by plotting proportional differences across MTHFR genotypes against metabolite concentrations at each quantile cut-off of the outcome for each region separately.

Statistical analyses were performed using SAS version 9.2 for Windows (SAS Institute, Inc.) and the open-source statistical program environment $\mathrm{R}$ with the package 'quantreg' to obtain quantile regression results ${ }^{(43)}$.

\section{Results}

Characteristics of the study population and data integrity

The average age of the total study population ( $n$ 5446) was $59 \cdot 0$ years, and $46 \cdot 1 \%$ were women. The UK study population had the highest mean age (65.4 years) and the Spanish study population had the lowest ( $54 \cdot 2$ years). The French study population only included women and the German study population represented the largest proportion of men (76.7\%) (data not shown). The proportion of current smokers was lowest in the Central European countries (16.4\%), and the proportion of individuals consuming $\geq 30 \mathrm{~g}$ alcohol/d was highest in the Southern European countries (22.2\%) (Table 1). The prevalence of the MTHFR 677TT genotype was 17.9\% in Southern Europe compared with $12.2 \%$ in Central Europe and $8.2 \%$ in Northern Europe (Table 1 ).

Spearman correlation coefficients $\left(\rho_{\mathrm{s}}\right)$, adjusted for age, sex, sub-study and prandial status between the vitamin $\mathrm{B}_{6}$ species, ranged from 0.61 to 0.71 , riboflavin correlated with FMN $\left(\rho_{\mathrm{s}}=0 \cdot 26\right)$, vitamin $\mathrm{B}_{12}$ with MMA $\left(\rho_{\mathrm{s}}=-0 \cdot 26\right)$ and tHcy $\left(\rho_{\mathrm{s}}=-0 \cdot 24\right)$ and folate with tHcy $\left(\rho_{\mathrm{s}}=-0 \cdot 30\right.$, all $P$ values $<0 \cdot 01)$. These correlations were essentially similar across the European regions and individual countries (data not shown).

Table 2 shows concentrations of B-vitamins and tHcy according to relevant demographic and lifestyle factors. Women had higher concentrations of vitamins $B_{2}$ and $B_{12}$ compared with men, whereas vitamin $\mathrm{B}_{6}$ and tHcy were higher in men. Furthermore, concentrations of vitamin $\mathrm{B}_{2}$, folate and tHcy were higher, whereas vitamin $\mathrm{B}_{12}$ was lower, in individuals older than 60 years compared with younger participants. Concentrations of all vitamins were lower among smokers compared with ex- and never smokers, whereas tHcy was lowest in never smokers. Those consuming $\geq 30 \mathrm{~g}$ alcohol/d had lower vitamin $\mathrm{B}_{2}, \mathrm{~B}_{12}$ and folate concentrations, but higher vitamin $\mathrm{B}_{6}$ and tHcy concentrations, compared with 
Table 1. Characteristics of the study population

\begin{tabular}{|c|c|c|c|c|c|}
\hline & \multirow[b]{2}{*}{ Total population } & \multicolumn{4}{|c|}{ Region* } \\
\hline & & North & Central & South & $P$ for difference \\
\hline$n$ & 5446 & 1222 & 2499 & 1725 & \\
\hline \multicolumn{6}{|l|}{ Sex } \\
\hline Female (\%) & $46 \cdot 1$ & $45 \cdot 5$ & $50 \cdot 4$ & $40 \cdot 9$ & $<0.001 \dagger$ \\
\hline \multicolumn{6}{|l|}{ Age (years) } \\
\hline Mean & $59 \cdot 0$ & $59 \cdot 7$ & 60.5 & $57 \cdot 1$ & $<0.001 \ddagger$ \\
\hline Range & $28.5-78.6$ & $30 \cdot 0-73 \cdot 3$ & $34.5-73.3$ & $28.5-78.6$ & \\
\hline \multicolumn{6}{|l|}{ Smoking (\%) } \\
\hline Unknown & 1.3 & 0.6 & $1 \cdot 1$ & $2 \cdot 0$ & \\
\hline Never & $42 \cdot 4$ & $38 \cdot 8$ & $43 \cdot 1$ & $44 \cdot 2$ & \\
\hline Ex & $34 \cdot 3$ & $31 \cdot 8$ & $39 \cdot 4$ & $28 \cdot 6$ & \\
\hline Current & $22 \cdot 0$ & $28 \cdot 9$ & $16 \cdot 4$ & $25 \cdot 2$ & $<0.001 \dagger$ \\
\hline \multicolumn{6}{|c|}{ Alcohol consumption $(\mathrm{g} / \mathrm{d}) \S$} \\
\hline Abstainers: $0 \mathrm{~g} / \mathrm{d}(\%)$ & $14 \cdot 3$ & $9 \cdot 7$ & $12 \cdot 7$ & $19 \cdot 8$ & \\
\hline$\geq 0.1 \mathrm{~g} / \mathrm{d}<4.9(\%)$ & $28 \cdot 5$ & 29.7 & $32 \cdot 3$ & $22 \cdot 1$ & \\
\hline$\geq 4.9 \mathrm{~g} / \mathrm{d}<30(\%)$ & $41 \cdot 8$ & $46 \cdot 9$ & 43.5 & 35.9 & \\
\hline$\geq 30 \mathrm{~g} / \mathrm{d}(\%)$ & $15 \cdot 4$ & $13 \cdot 7$ & 11.5 & $22 \cdot 2$ & $<0.001 \dagger$ \\
\hline \multicolumn{6}{|l|}{ MTHFR $677 \mathrm{C} \rightarrow \mathrm{T} \S$} \\
\hline CC (\%) & $41 \cdot 8$ & $47 \cdot 8$ & $44 \cdot 3$ & $34 \cdot 3$ & \\
\hline CT (\%) & $45 \cdot 0$ & $44 \cdot 0$ & 43.5 & $47 \cdot 8$ & \\
\hline TT (\%) & $13 \cdot 2$ & $8 \cdot 2$ & $12 \cdot 2$ & $17 \cdot 9$ & $<0.001 \dagger$ \\
\hline
\end{tabular}

abstainers and very light or occasional consumers of alcohol. Furthermore, plasma folate concentrations were lower among those with the MTHFR 677TT genotype compared with the CC and CT genotypes, whereas tHcy concentrations were higher in the MTHFR 677TT genotype. Concentrations of B-vitamins according to these demographic and lifestyle variables were similar within each region (data not shown). Finally, concentrations of vitamin $\mathrm{B}_{12}$ were lower, whereas concentrations of vitamins $\mathrm{B}_{2}, \mathrm{~B}_{6}$, and tHcy were higher among those with fasting blood samples.

\section{Patterns of B-vitamins, amino acids and related nutrients in Europe}

We investigated patterns across three European regions (North: Sweden and Denmark; Central: France, United Kingdom, the Netherlands and Germany; South: Italy, Spain and Greece). Sex-specific standardised median (5th-95th percentile) concentrations (Table 3) showed that folate concentrations were lowest in Northern Europe in both men (10.4 $(4.82-24 \cdot 2) \mathrm{nmol} / \mathrm{l})$ and women $(10 \cdot 7(4.73-31.5) \mathrm{nmol} / \mathrm{l})$ and highest concentrations were seen in Central Europe in both men $(14.6(6 \cdot 40-41.8) \mathrm{nmol} / \mathrm{l})$ and women (13.9 $(6 \cdot 05-44 \cdot 8) \mathrm{nmol} / \mathrm{l})$. However, the geographic pattern in tHcy concentrations - an inverse marker of folate and vitamin $B_{12}$ status - did not mirror patterns of folate concentrations, and tHcy concentrations were lowest in Northern Europe. Vitamin $B_{12}$ status was generally better in Northern Europe among men and women, as reflected by higher vitamin $B_{12}$ and lower MMA concentrations, but did not show a clear north-south gradient. Highest vitamin $\mathrm{B}_{2}$ concentrations were observed in men $(22 \cdot 2(11 \cdot 1-85 \cdot 0) \mathrm{nmol} / \mathrm{l})$ and women $(26.0(12.5-69 \cdot 5) \mathrm{nmol} / \mathrm{l})$ in the North, with decreasing concentrations from the north to south $\left(P_{\text {trend }}<0.001\right.$ in both sexes). Likewise, we observed that vitamin $\mathrm{B}_{6}$ concentrations were highest in Northern European women (74.4 $(33 \cdot 8-528) \mathrm{nmol} / \mathrm{l})$ and decreased from the north to south $\left(P_{\text {trend }}<0.001\right)$, whereas vitamin $\mathrm{B}_{6}$ concentrations in men were highest in Central Europe $(77 \cdot 3(41 \cdot 8-207) \mathrm{nmol} / \mathrm{l})$ (Table 3). In men, standardised median concentrations of the amino acids sarcosine, serine and glycine were lowest in Northern Europe, and showed increasing concentrations towards Southern Europe $\left(P_{\text {trend }}<0 \cdot 01\right.$ for all). No such clear patterns in amino acid concentrations were observed in women. Furthermore, Southern European men had the highest concentrations of the nutrients choline and betaine, with a significant north-south gradient for both nutrients, whereas these patterns were not observed for women (Table 3). After further adjustment for season of blood collection, smoking and alcohol intake, the standardised medians remained essentially the same (data not shown).

We also compared relative differences in B-vitamin concentrations between regions at the $0 \cdot 025,0 \cdot 05,0 \cdot 1,0 \cdot 25,0 \cdot 5,0 \cdot 75$, $0.9,0.95$ and 0.975 percentiles of the B-vitamin distributions (Fig. 1). Relative to Southern Europe, folate concentrations in Central and the Northern Europe showed a shift to higher levels of the upper part of the distribution (for Central Europe) and a shift to lower levels of the lower part of the distribution (for Northern Europe). Differences in tHcy 
Table 2. Plasma concentrations of vitamins $B_{2}, B_{6}, B_{12}$ and folate by demography, lifestyle and methylenetetrahydrofolate reductase (MTHFR) ${ }^{*}$ genotype (Medians and 5th-95th percentiles)

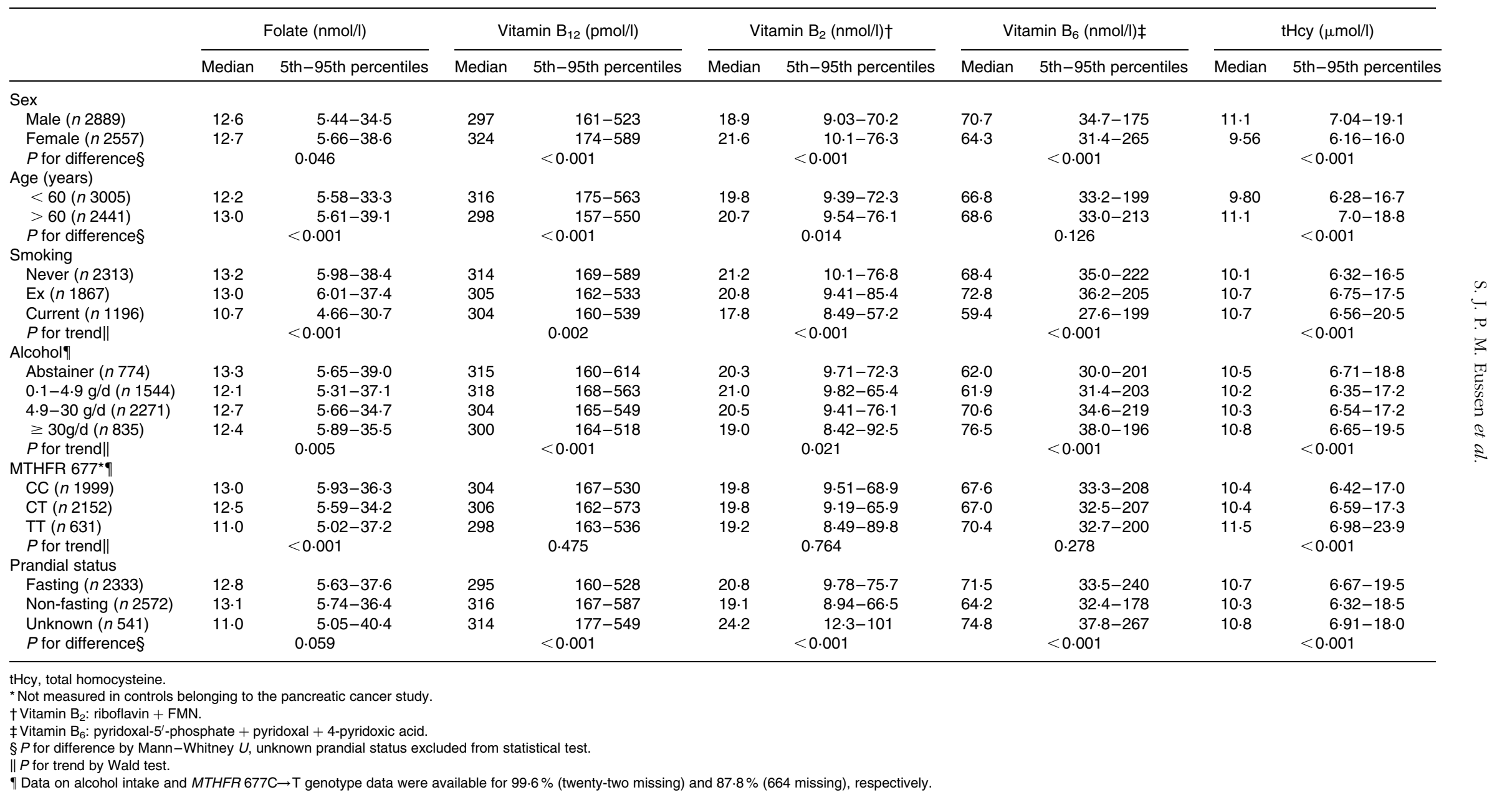


Table 3. Standardised plasma concentrations and trends across European regions* of B-vitamins and related metabolites

(Medians and 5th-95th percentiles)

\begin{tabular}{|c|c|c|c|c|c|c|c|c|c|c|c|c|c|c|c|c|c|c|}
\hline & \multicolumn{18}{|c|}{ Standardised median plasma concentrations } \\
\hline & \multicolumn{8}{|c|}{ Men } & \multirow[b]{3}{*}{$P_{\text {trend }} t$} & \multicolumn{8}{|c|}{ Women } & \multirow[b]{3}{*}{$P_{\text {trend }}{ }^{-}$} \\
\hline & \multicolumn{2}{|c|}{ All men ( $n$ 2889) } & \multicolumn{2}{|c|}{ North $(n 666)$} & \multicolumn{2}{|c|}{ Central ( $n$ 1204) } & \multicolumn{2}{|c|}{ South (n 1019) } & & \multicolumn{2}{|c|}{ All $(n$ 2557) } & \multicolumn{2}{|c|}{ North ( $n$ 556) } & \multicolumn{2}{|c|}{ Central ( $n$ 1295) } & \multicolumn{2}{|c|}{ South ( $n$ 706) } & \\
\hline & Median & $\begin{array}{c}\text { 5th-95th } \\
\text { percentiles }\end{array}$ & Median & $\begin{array}{c}\text { 5th-95th } \\
\text { percentiles }\end{array}$ & Median & $\begin{array}{c}\text { 5th-95th } \\
\text { percentiles }\end{array}$ & Median & $\begin{array}{l}\text { 5th-95th } \\
\text { percentiles }\end{array}$ & & Median & $\begin{array}{l}\text { 5th-95th } \\
\text { percentiles }\end{array}$ & Median & $\begin{array}{l}\text { 5th-95th } \\
\text { percentiles }\end{array}$ & Median & $\begin{array}{c}\text { 5th-95th } \\
\text { percentiles }\end{array}$ & Median & $\begin{array}{l}\text { 5th-95th } \\
\text { percentiles }\end{array}$ & \\
\hline \multicolumn{19}{|l|}{ Vitamins } \\
\hline $\begin{array}{l}\text { Folate } \\
(\mathrm{nmol} / \mathrm{l})\end{array}$ & 12.7 & $5 \cdot 63-34 \cdot 8$ & $10 \cdot 4$ & $4 \cdot 82-24 \cdot 2$ & 14.6 & $6 \cdot 40-41 \cdot 8$ & $12 \cdot 3$ & $5 \cdot 45-30 \cdot 8$ & $<0.001$ & 13.0 & $5 \cdot 72-39 \cdot 0$ & $10 \cdot 7$ & $4.73-31.5$ & 13.9 & $6 \cdot 05-44 \cdot 8$ & 13.7 & $6 \cdot 29-34 \cdot 1$ & $<0.001$ \\
\hline $\mathrm{B}_{12}(\mathrm{pmo} / \mathrm{l})$ & 298 & $164-509$ & 330 & $198-564$ & 286 & $157-462$ & 290 & $156-544$ & $<0.001$ & 326 & $177-571$ & 352 & $186-595$ & 311 & 173-559 & 330 & $182-583$ & 0.037 \\
\hline $\mathrm{B}_{2}(\mathrm{nmol} / \mathrm{l}) \neq$ & $19 \cdot 1$ & $9.59-71 \cdot 2$ & $22 \cdot 2$ & $11 \cdot 1-85.0$ & 20.5 & $10.5-76.8$ & $14 \cdot 6$ & $7.62-47.4$ & $<0.001$ & $21 \cdot 8$ & $10 \cdot 9-76 \cdot 5$ & $26 \cdot 0$ & $12.5-69.5$ & 23.0 & $12 \cdot 2-77 \cdot 9$ & $17 \cdot 2$ & $8 \cdot 11-84 \cdot 2$ & $<0.001$ \\
\hline $\mathrm{B}_{6}(\mathrm{nmol} / /) \S$ & $71 \cdot 2$ & $36 \cdot 7-180$ & $75 \cdot 1$ & $36 \cdot 5-209$ & $77 \cdot 3$ & $41 \cdot 8-207$ & $61 \cdot 6$ & $32 \cdot 2-134$ & $<0.001$ & $65 \cdot 6$ & $33 \cdot 7-292$ & 74.4 & $33 \cdot 8-528$ & $67 \cdot 8$ & $36 \cdot 8-320$ & 55.1 & $28 \cdot 8-111$ & $<0.001$ \\
\hline \multicolumn{19}{|l|}{$\begin{array}{c}\text { Amino acids } \\
(\mu \mathrm{mol} / \mathrm{l})\end{array}$} \\
\hline thcy & $11 \cdot 1$ & $7.73-19.4$ & $10 \cdot 3$ & $7 \cdot 32-16 \cdot 8$ & 11.4 & $7.91-20.2$ & 11.4 & $7.82-20.1$ & $<0.001$ & 9.66 & $6.51-17.3$ & 8.85 & $6 \cdot 06-14 \cdot 7$ & $10 \cdot 4$ & $7 \cdot 02-18.6$ & 9.09 & $6 \cdot 27-15 \cdot 0$ & 0.853 \\
\hline Cys & 273 & $228-328$ & 278 & $232-337$ & 272 & $227-324$ & 270 & $227-321$ & 0.001 & 262 & 219-322 & 269 & $225-327$ & 260 & $218-320$ & 258 & $214-316$ & $<0.001$ \\
\hline Met & $26 \cdot 6$ & $18 \cdot 2-39 \cdot 6$ & 25.9 & $17 \cdot 7-38 \cdot 4$ & $25 \cdot 1$ & $17.5-38.6$ & $28 \cdot 7$ & $20 \cdot 8-41 \cdot 9$ & $<0.001$ & 23.9 & $17 \cdot 0-36 \cdot 3$ & $23 \cdot 0$ & $16 \cdot 7-35 \cdot 0$ & 23.4 & $16 \cdot 1-36 \cdot 7$ & $25 \cdot 6$ & $19 \cdot 1-36 \cdot 6$ & $<0.001$ \\
\hline Serll & 133 & $91 \cdot 4-188$ & 123 & $85 \cdot 5-176$ & 125 & $88 \cdot 5-183$ & 142 & $104-194$ & $<0.001$ & 143 & $95 \cdot 8-206$ & 129 & $88.5-183$ & 147 & $97 \cdot 9-211$ & 143 & $98 \cdot 3-209$ & 0.003 \\
\hline Glyll & 256 & $182-371$ & 234 & $177-367$ & 251 & $174-377$ & 263 & $198-370$ & $<0.001$ & 293 & $190-507$ & 275 & $174-496$ & 301 & $195-521$ & 285 & $194-486$ & 0.965 \\
\hline Sarll & 1.60 & $0.98-2.89$ & 1.44 & $0.96-2.57$ & 1.53 & $0.98-2.90$ & 1.71 & $1.00-2.94$ & $<0.001$ & 1.34 & $0.81-2.47$ & 1.31 & $0.81-2 \cdot 11$ & 1.29 & $0.78-2.33$ & 1.46 & $0.94-2.89$ & 0.022 \\
\hline \multicolumn{19}{|l|}{$\begin{array}{l}\text { Nutrients or } \\
\text { intermedi- } \\
\text { ates }(\mu \mathrm{mol} / \mathrm{l})\end{array}$} \\
\hline MMA & 0.18 & $0.12-0.36$ & 0.17 & $0.11-0.34$ & 0.18 & $0.12-0.39$ & 0.17 & $0.11-0.33$ & 0.999 & 0.17 & $0.11-0.33$ & 0.17 & $0.11-0.28$ & 0.18 & $0.12-0.36$ & 0.17 & $0.11-0.31$ & 0.999 \\
\hline Cholineף & 9.76 & $6 \cdot 57-15 \cdot 1$ & 9.04 & $6 \cdot 27-13 \cdot 5$ & 9.82 & $6 \cdot 46-15 \cdot 6$ & $10 \cdot 5$ & $7 \cdot 28-16 \cdot 3$ & $<0.001$ & $9 \cdot 17$ & $6 \cdot 19-14.5$ & 8.65 & $5.45-12.5$ & $9 \cdot 37$ & $6 \cdot 29-15 \cdot 1$ & 9.26 & $6.54-15.1$ & 0.038 \\
\hline Betaineף & 35.9 & $23 \cdot 1-58 \cdot 2$ & 34.9 & $23 \cdot 1-57 \cdot 7$ & 35.5 & $22 \cdot 9-56 \cdot 9$ & 38.3 & $23 \cdot 1-61 \cdot 6$ & $<0.001$ & $29 \cdot 2$ & $16 \cdot 8-48 \cdot 1$ & 29.0 & $16 \cdot 7-46 \cdot 4$ & $28 \cdot 1$ & $16 \cdot 8-46 \cdot 7$ & 31.9 & $16 \cdot 7-51 \cdot 1$ & 0.007 \\
\hline DMGף & 3.72 & $2.45-6.05$ & 3.67 & $2.33-5.64$ & 3.68 & $2.42-5.96$ & 3.86 & $2 \cdot 61-6.49$ & 0.012 & 3.24 & $2 \cdot 10-5 \cdot 42$ & $3 \cdot 21$ & $2 \cdot 17-5 \cdot 39$ & 3.26 & $2 \cdot 09-5.21$ & 3.28 & $1.96-5.88$ & 0.478 \\
\hline Cystathionine & 0.18 & $0.09-0.46$ & 0.20 & $0.10-0.63$ & 0.18 & $0.10-0.43$ & 0.17 & $0.09-0.39$ & $<0.001$ & 0.16 & $0.08-0.42$ & 0.17 & $0.08-0.51$ & 0.16 & $0.08-0.42$ & 0.16 & $0.09-0.36$ & 0.048 \\
\hline
\end{tabular}

tHcy, total homocysteine; MMA, methylmalonic acid; DMG, dimethylglycine.

"North: Sweden and Denmark; Central: France, United Kingdom, the Netherlands and Germany; South: Italy, Spain and Greece.

$\dagger$ By Quantile regression, Wald test.

$\mp$ Vitamin $B_{2}$ : riboflavin $+F M N$ not measured in controls matched to lung cancer.

$\S$ Vitamin $B_{6}$ : pyridoxal-5'-phosphate + pyridoxal + 4-pyridoxic acid.

Not measured in controls matched to gastric and colorectal cancer. 

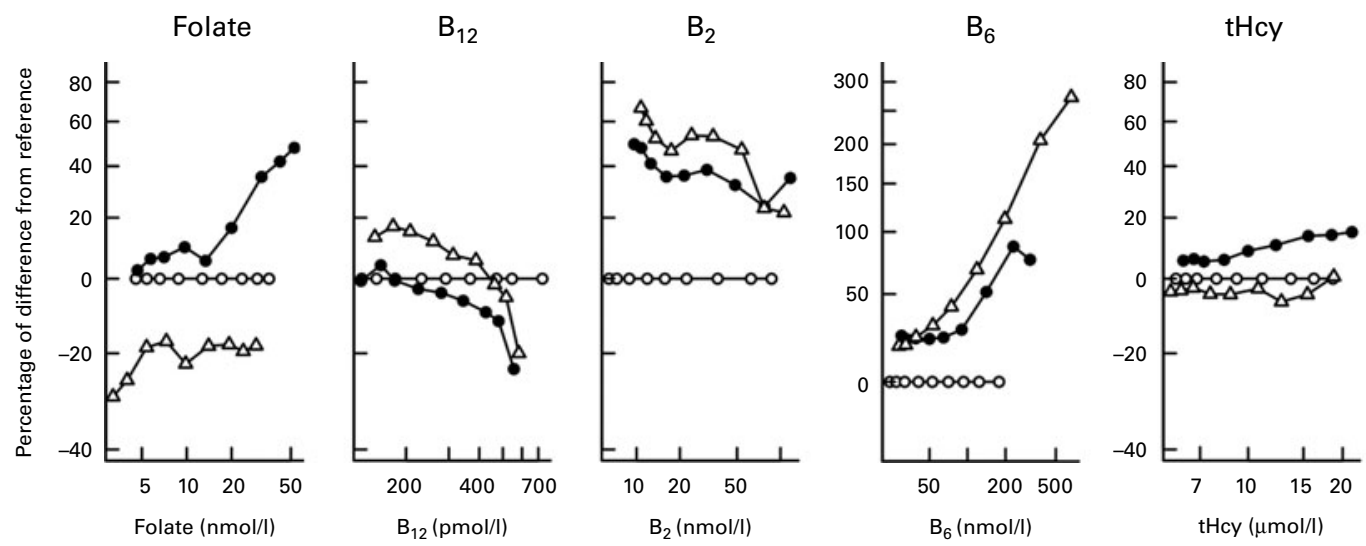

MMA

Fig. 1. Plasma concentrations of B-vitamins across Western European regions by quantile regression. Concentrations of the vitamins and their markers are shown on the $x$-axis, and the differences between the European regions are shown on the $y$-axis. The $0.025,0.05,0.1,0.25,0.5,0.75,0.9,0.95$ and 0.975 percentiles are reflected by the dots. The model is adjusted for age, sex and sub-study and prandial status. Southern Europe is the reference category. thcy, total homocysteine; MMA, methylmalonic acid. - -, South (reference); $-\bullet-$, Central; $\triangle$, North.

concentrations were small. The profiles for markers of vitamin $\mathrm{B}_{12}$ status were complementary to each other, with the lowest vitamin $\mathrm{B}_{12}$ and highest MMA concentrations in Central Europe. The relative regional differences in vitamin $\mathrm{B}_{2}$ concentrations over the whole distribution range were symmetrical with higher levels for Central and the Northern Europe. There were regional differences in vitamin $\mathrm{B}_{6}$ concentrations, with highest levels in Central and the Northern Europe. The distribution curve was asymmetrical and showed most pronounced differences at higher concentrations.

Analyses of the proportion of individuals with deficient B-vitamin status, as based on the $2 \cdot 5$ th percentile distribution of the total study population, revealed that deficiencies of vita$\min \mathrm{B}_{2}(6 \cdot 2 \%$ with concentrations $<7.9 \mathrm{nmol} / \mathrm{l})$ and vitamin $\mathrm{B}_{6}(4.5 \%$ with concentrations $<28.9 \mathrm{nmol} / \mathrm{l})$ were most prevalent in Southern European countries, whereas vitamin $\mathrm{B}_{12}$ and folate deficiency were more frequently observed in Central ( $2.9 \%$ with concentrations $<140 \mathrm{pmol} / \mathrm{l})$ and Northern Europe ( $4.6 \%$ with concentrations $<4.6 \mathrm{nmol} / \mathrm{l})$, respectively (data not shown).

\section{Distribution of folate according to methylenetetrahydrofolate reductase $677 C \rightarrow T$ genotype}

There was an increasing north-south gradient for the number of T-alleles of the MTHFR $677 \mathrm{C} \rightarrow \mathrm{T}$ genotype (Table 1). We investigated the distribution of folate and tHcy according to the MTHFR $677 \mathrm{C} \rightarrow \mathrm{T}$ genotype across regions by quantile regression (Table 4 and Fig. S1, available online). In the total study population and in each region, there was a trend towards lower folate and higher tHcy concentrations according to the number of T-alleles (Table 4). Further, the distribution was asymmetric, with the largest differences in the lower quantiles of folate and the highest quantiles in tHcy. The asymmetric profile and differences were most pronounced in Southern Europe (Fig. S1, available online). Thus, the MTHFR 677TT genotype was associated with an increased prevalence of subjects with low folate and high tHcy, suggesting impaired folate status, and exerted the largest differences on distribution of these indices in populations with the highest MTHFR $677 \mathrm{~T}$ allele frequency.

Table 4. Plasma folate and total homocysteine (tHcy) concentrations according to the methylenetetrahydrofolate reductase $(M T H F R) 677 \mathrm{C} \rightarrow \mathrm{T}$ genotype across European regions*

(Medians and 5th-95th percentiles)

\begin{tabular}{|c|c|c|c|c|c|c|c|}
\hline \multirow[b]{2}{*}{ MTHFR 677} & \multicolumn{2}{|c|}{ North (n 1221) } & \multicolumn{2}{|c|}{ Central ( $n$ 1221) } & \multicolumn{2}{|c|}{ South ( $n$ 935) } & \multirow[b]{2}{*}{$P$ for difference $\dagger$} \\
\hline & Median & 5th-95th percentiles & Median & 5th-95th percentiles & Median & 5th-95th percentiles & \\
\hline \multicolumn{8}{|c|}{ Plasma folate concentrations } \\
\hline CC & 9.93 & $4.78-31.9$ & $13 \cdot 1$ & $6 \cdot 23-39 \cdot 4$ & $13 \cdot 5$ & $6 \cdot 10-31 \cdot 2$ & \\
\hline $\mathrm{CT}$ & $10 \cdot 0$ & $4 \cdot 24-26 \cdot 5$ & $12 \cdot 6$ & $5.95-36.5$ & $12 \cdot 6$ & $5 \cdot 66-28 \cdot 4$ & \\
\hline TT & $9 \cdot 02$ & $4.09-23.5$ & $11 \cdot 4$ & $4 \cdot 96-45 \cdot 7$ & $10 \cdot 4$ & $4 \cdot 64-26 \cdot 3$ & $<0.0001$ \\
\hline \multicolumn{8}{|c|}{ Plasma tHcy concentrations } \\
\hline $\mathrm{CC}$ & 9.65 & $6 \cdot 23-16 \cdot 8$ & $9 \cdot 75$ & $6 \cdot 57-15 \cdot 6$ & $9 \cdot 16$ & $5 \cdot 92-14.8$ & \\
\hline CT & $9 \cdot 76$ & $6 \cdot 51-18 \cdot 0$ & $10 \cdot 0$ & $6 \cdot 75-15 \cdot 6$ & $8 \cdot 85$ & $6 \cdot 05-15 \cdot 4$ & \\
\hline TT & $10 \cdot 6$ & $6 \cdot 62-20.4$ & $10 \cdot 7$ & $6 \cdot 73-21 \cdot 0$ & $9 \cdot 82$ & $6 \cdot 21-23 \cdot 7$ & $<0.0001$ \\
\hline
\end{tabular}

${ }^{*}$ North: Sweden and Denmark; Central: France, United Kingdom, the Netherlands and Germany; South: Italy, Spain and Greece.

$\dagger P$ for difference by Kruskal-Wallis test. 


\section{Discussion}

\section{Principal findings}

The present study is the largest to date to investigate geographical patterns in blood concentrations of B-vitamins, amino acids and other metabolites related to one-carbon metabolism. Folate concentrations were lowest in Northern European countries, with increasing concentrations from north to south in women. Vitamins $\mathrm{B}_{2}$ and $\mathrm{B}_{6}$ concentrations were highest in Northern European countries and showed a clear decreasing north-south gradient in both men and women. Concentrations of tHcy, sarcosine, serine and glycine in men were lowest in Northern Europe, and increased towards Southern Europe. The highest concentrations of the nutrients choline and betaine were observed in Southern Europe, but there was no significant north-south gradient for choline in men.

\section{$B$-vitamin status}

Food patterns, traditions of vitamin supplementation and lifestyle factors differ greatly across European regions. Compared with the overall EPIC study population, the dietary pattern of Italy and Greece is characterised by a higher consumption of plant foods - the main source of folate - and a lower consumption of animal - the main source of vitamin $\mathrm{B}_{12}-$ and processed foods. Diets in France and Spain contain relatively high amounts of plant foods and animal products, whereas the UK general population has a relatively high consumption of tea, sauces, cakes, soft drinks, margarine and butter. Finally, the diet in the Nordic countries, The Netherlands, Germany and the UK general population is relatively high in potatoes and animal, processed and sweetened/refined foods ${ }^{(44,45)}$.

A lower intake of fruits and vegetables in Northern Europe may explain the tendency towards lower folate concentrations in the Northern region, and is in line with the previously reported lower folate intake ${ }^{(20,23)}$ and plasma levels ${ }^{(21)}$ in Northern countries. The higher plasma vitamin $\mathrm{B}_{12}$ concentrations in Northern Europe agree with higher vitamin $\mathrm{B}_{12}$ intake in Northern countries ${ }^{(46)}$ and probably reflect a higher meat intake in this region ${ }^{(44)}$. Lower vitamin $\mathrm{B}_{2}$ concentrations observed in Southern countries could be partially explained by a lower consumption of dairy products ${ }^{(47)}$. These findings are in line with results from the SENECA study showing a higher consumption of dairy products in Northern countries compared with Southern countries ${ }^{(48)}$, although the EPIC population had higher dairy intakes in Southern countries ${ }^{(47)}$, as well as higher intakes of vegetables, fruits and cereals, which are also sources of vitamin $\mathrm{B}_{2}{ }^{\left({ }^{(49)}\right.}$ Vitamin $\mathrm{B}_{6}$ concentrations were lower in Southern countries compared with Northern countries, and differences between regions became larger at the higher end of the vitamin $\mathrm{B}_{6}$ distribution, where the concentrations are similar to concentrations obtained by vitamin $\mathrm{B}_{6}$ supplements ${ }^{(50,51)}$.

A subsample of the EPIC population revealed a north-south gradient in vitamin supplement use, with higher consumption in Northern European countries than in Southern European countries, and higher consumption for women than for men ${ }^{(52)}$, which could also partially explain the higher concentrations observed for vitamins $\mathrm{B}_{2}, \mathrm{~B}_{6}$ and $\mathrm{B}_{12}$, but not for folate in the Northern region.

Mandatory folic acid fortification has not been implemented in Western European countries. However, national policies on voluntary folic acid fortification vary considerably ${ }^{(53)}$, which may also affect folate status in individuals who do not use supplements ${ }^{(54)}$. In addition to higher folate status, mandatory ${ }^{(55)}$ or voluntary food folic acid fortification ${ }^{(54)}$ also influences the concentrations of other B-vitamins, tHcy and nutrients involved in one-carbon metabolism ${ }^{(3)}$. However, it is unclear to what extent any voluntary fortification might have affected the between-region differences in the present study.

One study observed a lower folate intake in Southern European countries in the summer compared with Northern countries $^{(23)}$. This may be explained by the fact that green leafy vegetables, one of the major dietary sources of folate in those countries, are broadly known as an early-spring or late autumn crop $^{(23)}$. Adjustment for season of blood collection did not affect the trends observed in the present study. Smoking behaviour ${ }^{(11)}$ and alcohol consumption ${ }^{(13)}$ are known lifestyle factors that affect B-vitamin status. Even though there were differences in smoking behaviour and alcohol consumption across regions, additional adjustment for these lifestyle factors did not materially alter the estimated patterns across regions.

\section{Amino acids and other nutrients}

Folate-dependent one-carbon metabolism is closely linked to pathways involving amino acids like homocysteine, methionine, serine and glycine, and donors of one-carbon units such as choline, betaine and related methylamines ${ }^{(3)}$. Therefore, it is important to consider not only B-vitamins, but also amino acids, and other nutrients and metabolites in epidemiological studies on one-carbon metabolism. Patterns of plasma concentrations of the amino acids tHcy, methionine, sarcosine, serine and glycine were consistent, with the lowest concentrations in Northern Europe and increasing concentrations towards Southern Europe in men. Likewise, men in Southern Europe had the highest concentrations of the nutrients choline and betaine, whereas in women, betaine and choline concentrations were highest in Southern and the Central Europe, respectively. The high choline concentrations are likely to be attributed to high egg consumption ${ }^{(56)}$, which has been reported to be highest in Spain ${ }^{(57)}$.

\section{Methylenetetrahydrofolate reductase $677 \mathrm{C} \rightarrow T$ genotype and folate status}

Prevalence of the MTHFR 677TT genotype in white populations in Europe, North America and Australia varies from 8 to $20 \%$, and a trend of increasing frequency of the TT genotype has been observed from north to south Europe ${ }^{(58)}$, which agrees with the present study. The TT variant, which was most prevalent in Southern Europe, was associated with lower folate and higher tHcy concentrations, as has previously been shown ${ }^{(59)}$. Folate and tHcy are the metabolites that are most strongly 
influenced by MTHFR genotype ${ }^{(10)}$. Although one would thereby expect lower folate status in the South as well, we observed that folate concentrations were higher in the South, suggesting that dietary factors are stronger determinants for folate status than this specific genetic factor.

\section{Limitations and strengths}

The EPIC study investigates the relation of diet and lifestyle with cancer incidence, and was as such not designed to be representative of the general European population. The study cohort comprised individuals recruited from the general population, blood donors (Spain and Italy), teachers and school workers (France), a health-conscious population (UK) and women participating in a breast cancer screening programme (The Netherlands and Italy) ${ }^{(23)}$. The present study population may therefore reflect a more health-conscious part of the European population. The patterns observed may consequently have been under- or overestimated as a result of potential selection bias. An important strength of the present study is the large sample size of individuals recruited from several Western European countries. Nevertheless, the present study cannot provide any estimates of potential differences in disease risk profiles across the European regions as we lack data on disease status or use of medication that may affect metabolite concentrations. Furthermore, the impact of alcohol consumption on the observed patterns could not be investigated in further detail as we did not have data specifically on the consumption of beer, wine or spirits. Finally, it is known that menopausal status affects choline concentrations ${ }^{(60)}$. However, the present study lacked statistical power to investigate whether postmenopausal status affected choline concentrations across the European regions.

A standardised protocol for the collection and storage of blood was used in the majority of participating study centres; all blood samples were collected in citrate plasma and all biochemical analyses were performed in one laboratory. This reduced pre-analytical variability due to differences in sample handling and eliminated inter-assay variations. Recently, the same laboratory investigated the stability of metabolites related to one-carbon metabolism at room temperature and during long-term storage ${ }^{(26)}$. The results of that study underscore the importance of adequate sample handling and storage in epidemiological and clinical studies ${ }^{(26)}$. Folate, species of vitamins $\mathrm{B}_{2}$ and $\mathrm{B}_{6}$ and choline appear to be unstable during storage ${ }^{(26)}$. However, the sum of riboflavin and FMN and the sum of pyridoxal-5'-phosphate, PL and 4-pyridoxic acid are stable, and we therefore presented the sum of these species as measures of vitamins $B_{2}$ and $B_{6}$ status in the present investigation. In addition, concentrations of choline, but not betaine, increase with increasing storage time ${ }^{(26)}$. Therefore, higher concentrations of both choline and betaine observed in Central European countries are more likely explained by a higher dietary intake of choline than by pre-analytical errors. The observed correlations between metabolites were essentially the same when calculated within countries, regions or the total study population, observations that support data integrity.

\section{Conclusions}

The present study covers a large geographical area in Europe, and presents a comprehensive spectrum of B-vitamins, amino acids and other nutrients involved in one-carbon metabolism. The study reveals clear decreasing north-south gradients of vitamins $\mathrm{B}_{2}$ and $\mathrm{B}_{6}$, and increasing gradients of folate and the majority of amino acids included in the present study. These differences may reflect distinct dietary and lifestyle patterns between regions, and may be relevant for the study of regional differences in chronic disease incidence in Western Europe.

\section{Supplementary material}

To view supplementary material for this article, please visit http://dx.doi.org/10.1017/S0007114512004990

\section{Acknowledgements}

The work was supported by the European Commission: Public Health and Consumer Protection Directorate 1993-2004; Research Directorate-General 2005; Ligue contre le Cancer (France); Société 3M (France); Mutuelle Générale de l'Education Nationale; Institut National de la Santé et de la Recherche Médicale (INSERM); German Cancer Aid; German Cancer Research Center (DKFZ); German Federal Ministry of Education and Research; Danish Cancer Society; Health Research Fund (FIS) of the Spanish Ministry of Health (RTICC (RD06/0020), the participating regional governments from Asturias, Andalucía, Murcia, Navarra and Vasco Country and the Catalan Institute of Oncology of Spain; Cancer Research UK; Medical Research Council, UK; Stroke Association, UK; British Heart Foundation; Department of Health, UK; Food Standards Agency, UK; Wellcome Trust, UK; the Hellenic Health Foundation and the Stavros Niarchos Foundation, Greece; Italian Association for Research on Cancer (AIRC); Compagnia San Paolo, Italy; Dutch Ministry of Public Health, Welfare and Sports; Dutch Ministry of Health; Dutch Prevention Funds; LK Research Funds; Dutch ZON (Zorg Onderzoek Nederland); World Cancer Research Fund (WCRF); Swedish Cancer Society; Swedish Scientific Council; Regional Government of Skåne, Sweden; Norwegian Cancer Society; Foundation to promote research into functional vitamin $B_{12}$-deficiency, Norway. The authors' responsibilities were as follows: S. J. P. M. E., R. M. N., Ø. M., S. H., N. IJ., K. M.,̊. F., A. U., P. M. U., P. B., M. J., B. B. d. M., P. V., S.-C. C. and S. E. V. consituted the writing group, conducted the statistical analysis and prepared the manuscript; all other authors contriuted to and/or provided comments and suggestions on the intermediate and final manuscripts. All authors read and approved the final manuscript. None of the authors reported a personal or financial conflict of interest. 


\section{References}

1. Wu G (2009) Amino acids: metabolism, functions, and nutrition. Amino Acids 37, 1-17.

2. Wolff T, Witkop CT, Miller T, et al. (2009) Folic acid supplementation for the prevention of neural tube defects: an update of the evidence for the U.S. Preventive Services Task Force. Ann Intern Med 150, 632-639.

3. Ueland PM (2011) Choline and betaine in health and disease. J Inherit Metab Dis 34, 3-15.

4. Konstantinova SV, Tell GS, Vollset SE, et al. (2008) Divergent associations of plasma choline and betaine with components of metabolic syndrome in middle age and elderly men and women. J Nutr 138, 914-920.

5. Voutilainen S, Virtanen JK, Rissanen TH, et al. (2004) Serum folate and homocysteine and the incidence of acute coronary events: the Kuopio Ischaemic Heart Disease Risk Factor Study. Am J Clin Nutr 80, 317-323.

6. Tucker KL, Qiao N, Scott T, et al. (2005) High homocysteine and low $\mathrm{B}$ vitamins predict cognitive decline in aging men: the Veterans Affairs Normative Aging Study. Am J Clin Nutr 82, 627-635.

7. van Meurs JB, Dhonukshe-Rutten RA, Pluijm SM, et al. (2004) Homocysteine levels and the risk of osteoporotic fracture. $N$ Engl J Med 350, 2033-2041.

8. Kim YI (2007) Folate and colorectal cancer: an evidencebased critical review. Mol Nutr Food Res 51, 267-292.

9. Sreekumar A, Poisson LM, Rajendiran TM, et al. (2009) Metabolomic profiles delineate potential role for sarcosine in prostate cancer progression. Nature 457, 910-914.

10. Hustad S, Midttun O, Schneede J, et al. (2007) The methylenetetrahydrofolate reductase $677 \mathrm{C} \rightarrow \mathrm{T}$ polymorphism as a modulator of a $\mathrm{B}$ vitamin network with major effects on homocysteine metabolism. Am J Hum Genet 80, 846-855.

11. Ulvik A, Ebbing M, Hustad S, et al. (2010) Long- and shortterm effects of tobacco smoking on circulating concentrations of B vitamins. Clin Chem 56, 755-763.

12. Larsson SC, Giovannucci E \& Wolk A (2005) Vitamin $B_{6}$ intake, alcohol consumption, and colorectal cancer: a longitudinal population-based cohort of women. Gastroenterology 128, 1830-1837.

13. Giovannucci E (2004) Alcohol, one-carbon metabolism, and colorectal cancer: recent insights from molecular studies. J Nutr 134, 2475S-2481S.

14. Nurk E, Tell GS, Vollset SE, et al. (2004) Changes in lifestyle and plasma total homocysteine: the Hordaland Homocysteine Study. Am J Clin Nutr 79, 812-819.

15. Freisling H, Fahey MT, Moskal A, et al. (2010) Regionspecific nutrient intake patterns exhibit a geographical gradient within and between European countries. J Nutr 140, $1280-1286$

16. Orfanos P, Naska A, Trichopoulou A, et al. (2009) Eating out of home: energy, macro- and micronutrient intakes in 10 European countries. The European Prospective Investigation into Cancer and Nutrition. Eur J Clin Nutr 63, Suppl. 4, S239-S262.

17. Sieri S, Krogh V, Saieva C, et al. (2009) Alcohol consumption patterns, diet and body weight in 10 European countries. Eur J Clin Nutr 63, Suppl. 4, S81-S100.

18. Yusuf S, Hawken S, Ounpuu S, et al. (2004) Effect of potentially modifiable risk factors associated with myocardial infarction in 52 countries (the INTERHEART study): casecontrol study. Lancet 364, 937-952.

19. Knoops KT, de Groot LC, Kromhout D, et al. (2004) Mediterranean diet, lifestyle factors, and 10-year mortality in elderly
European men and women: the HALE project. JAMA 292 , $1433-1439$.

20. de Bree A, van Dusseldorp M, Brouwer IA, et al. (1997) Folate intake in Europe: recommended, actual and desired intake. Eur J Clin Nutr 51, 643-660.

21. Dhonukshe-Rutten RA, de Vries JH, de Bree A, et al. (2009) Dietary intake and status of folate and vitamin $\mathrm{B}_{12}$ and their association with homocysteine and cardiovascular disease in European populations. Eur J Clin Nutr 63, 18-30.

22. Olsen A, Halkjaer J, van Gils $\mathrm{CH}$, et al. (2009) Dietary intake of the water-soluble vitamins $\mathrm{B}_{1}, \mathrm{~B}_{2}, \mathrm{~B}_{6}, \mathrm{~B}_{12}$ and $\mathrm{C}$ in 10 countries in the European Prospective Investigation into Cancer and Nutrition. Eur J Clin Nutr 63, Suppl. 4, S122-S149.

23. Park JY, Nicolas G, Freisling H, et al. (2012) Comparison of standardised dietary folate intake across ten countries participating in the European Prospective Investigation into Cancer and Nutrition. Br J Nutr 108, 552-569.

24. van der Wielen RP, Lowik MR, Haller J, et al. (1996) Vitamin B-6 malnutrition among elderly Europeans: the SENECA study. J Gerontol A Biol Sci Med Sci 51, B417-B424.

25. de Groot LC, Hautvast JG \& van Staveren WA (1992) Nutrition and health of elderly people in Europe: the EURONUT-SENECA Study. Nutr Rev 50, 185-194.

26. Hustad S, Eussen S, Midttun O, et al. (2012) Kinetic modeling of storage effects on biomarkers related to B vitamin status and one-carbon metabolism. Clin Chem 58, 402-410.

27. Riboli E \& Kaaks R (1997) The EPIC Project: rationale and study design. European Prospective Investigation into Cancer and Nutrition. Int J Epidemiol 26, Suppl. 1, S6-S14.

28. Hannisdal R, Ueland PM, Eussen SJ, et al. (2009) Analytical recovery of folate degradation products formed in human serum and plasma at room temperature. J Nutr 139, 1415-1418.

29. Riboli E, Hunt KJ, Slimani N, et al. (2002) European Prospective Investigation into Cancer and Nutrition (EPIC): study populations and data collection. Public Health Nutr 5, 1113-1124.

30. Midttun O, Hustad S \& Ueland PM (2009) Quantitative profiling of biomarkers related to B-vitamin status, tryptophan metabolism and inflammation in human plasma by liquid chromatography/tandem mass spectrometry. Rapid Commun Mass Spectrom 23, 1371-1379.

31. Holm PI, Ueland PM, Kvalheim G, et al. (2003) Determination of choline, betaine, and dimethylglycine in plasma by a high-throughput method based on normal-phase chromatography-tandem mass spectrometry. Clin Chem 49, 286-294

32. Midttun O, Hustad S, Solheim E, et al. (2005) Multianalyte quantification of vitamin $\mathrm{B}_{6}$ and $\mathrm{B}_{2}$ species in the nanomolar range in human plasma by liquid chromatography-tandem mass spectrometry. Clin Chem 51, 1206-1216.

33. Ueland PM, Midttun O, Windelberg A, et al. (2007) Quantitative profiling of folate and one-carbon metabolism in large-scale epidemiological studies by mass spectrometry. Clin Chem Lab Med 45, 1737-1745.

34. Windelberg A, Arseth O, Kvalheim G, et al. (2005) Automated assay for the determination of methylmalonic acid, total homocysteine, and related amino acids in human serum or plasma by means of methylchloroformate derivatization and gas chromatography-mass spectrometry. Clin Chem 51, 2103-2109.

35. Kelleher BP \& Broin SD (1991) Microbiological assay for vitamin $\mathrm{B}_{12}$ performed in 96-well microtitre plates. J Clin Pathol 44, 592-595. 
36. Molloy AM \& Scott JM (1997) Microbiological assay for serum, plasma, and red cell folate using cryopreserved, microtiter plate method. Methods Enzymol 281, 43-53.

37. Fredriksen A, Meyer K, Ueland PM, et al. (2007) Large-scale population-based metabolic phenotyping of thirteen genetic polymorphisms related to one-carbon metabolism. Hum Mutat 28, 856-865.

38. Meyer K, Fredriksen A \& Ueland PM (2004) High-level multiplex genotyping of polymorphisms involved in folate or homocysteine metabolism by matrix-assisted laser desorption/ionization mass spectrometry. Clin Chem 50, $391-402$.

39. Foraker AB, Khantwal CM \& Swaan PW (2003) Current perspectives on the cellular uptake and trafficking of riboflavin. Adv Drug Deliv Rev 55, 1467-1483.

40. Coburn SP (1996) Modeling vitamin $\mathrm{B}_{6}$ metabolism. $A d v$ Food Nutr Res 40, 107-132.

41. Rothman K \& Greenland S (1998) Measures of Effect and Measures of Association. Philadelphia, PA: Lippincott-Raven Publishers.

42. Koenker R \& Hallock K (2001) Quantile regression. J Econ Perspect 15, 143-156.

43. Ihaka R \& Gentleman R (1996) R: a language for data analysis and graphics. J Comput Graph Stat 5, 299-314.

44. Linseisen J, Kesse E, Slimani N, et al. (2002) Meat consumption in the European Prospective Investigation into Cancer and Nutrition (EPIC) cohorts: results from 24-hour dietary recalls. Public Health Nutr 5, 1243-1258.

45. Slimani N, Fahey M, Welch AA, et al. (2002) Diversity of dietary patterns observed in the European Prospective Investigation into Cancer and Nutrition (EPIC) project. Public Health Nutr 5, 1311-1328.

46. Vinas BR, Barba LR, Ngo J, et al. (2011) Projected prevalence of inadequate nutrient intakes in Europe. Ann Nutr Metab 59, 84-95.

47. Hjartaker A, Lagiou A, Slimani N, et al. (2002) Consumption of dairy products in the European Prospective Investigation into Cancer and Nutrition (EPIC) cohort: data from 35955 24hour dietary recalls in 10 European countries. Public Health Nutr 5, 1259-1271.

48. Schroll K, Carbajal A, Decarli B, et al. (1996) Food patterns of elderly Europeans. SENECA Investigators. Eur J Clin Nutr $\mathbf{5 0}$ Suppl. 2, S86-S100.

49. Pan WH, Lee MM, Yu SL, et al. (1992) Foods predictive of nutrient intake in Chinese diet in Taiwan: II. Vitamin A, vitamin $\mathrm{B}_{1}$, vitamin $\mathrm{B}_{2}$, vitamin $\mathrm{C}$ and calcium. Int $J$ Epidemiol 21, 929-934.

50. Bor MV, Refsum H, Bisp MR, et al. (2003) Plasma vitamin $B_{6}$ vitamers before and after oral vitamin $\mathrm{B}_{6}$ treatment: a randomized placebo-controlled study. Clin Chem 49, 155-161.

51. Lumeng L, Lui A \& Li TK (1980) Plasma content of $\mathrm{B}_{6}$ vitamers and its relationship to hepatic vitamin $\mathrm{B}_{6}$ metabolism. J Clin Invest 66, 688-695.

52. Skeie G, Braaten T, Hjartaker A, et al. (2009) Use of dietary supplements in the European Prospective Investigation into Cancer and Nutrition calibration study. Eur J Clin Nutr 63, Suppl. 4, S226-S238.

53. General ECHaCPD- (2006) Discussion Paper on the Setting of Maximum and Minimum Amounts for Vitamins and Minerals in Foodstuffs. Brussels: European Communities.

54. Hoey L, McNulty H, Askin N, et al. (2007) Effect of a voluntary food fortification policy on folate, related $\mathrm{B}$ vitamin status, and homocysteine in healthy adults. Am J Clin Nutr 86, $1405-1413$.

55. Pfeiffer CM, Caudill SP, Gunter EW, et al. (2005) Biochemical indicators of B vitamin status in the US population after folic acid fortification: results from the National Health and Nutrition Examination Survey 1999-2000. Am J Clin Nutr 82, 442-450.

56. Konstantinova SV, Tell GS, Vollset SE, et al. (2008) Dietary patterns, food groups, and nutrients as predictors of plasma choline and betaine in middle-aged and elderly men and women. Am J Clin Nutr 88, 1663-1669.

57. Pala V, Krogh V, Berrino F, et al. (2009) Meat, eggs, dairy products, and risk of breast cancer in the European Prospective Investigation into Cancer and Nutrition (EPIC) cohort. Am J Clin Nutr 90, 602-612.

58. Botto LD \& Yang Q (2000) 5,10-Methylenetetrahydrofolate reductase gene variants and congenital anomalies: a HuGE review. Am J Epidemiol 151, 862-877.

59. Ulvik A, Ueland PM, Fredriksen A, et al. (2007) Functional inference of the methylenetetrahydrofolate reductase $677 \mathrm{C}>\mathrm{T}$ and $1298 \mathrm{~A}>\mathrm{C}$ polymorphisms from a largescale epidemiological study. Hum Genet 121, 57-64.

60. Wallace JM, McCormack JM, McNulty H, et al. (2012) Choline supplementation and measures of choline and betaine status: a randomised, controlled trial in postmenopausal women. BrJ Nutr 108, 1264-1271. 